\title{
LA DEFINICIÓN DE USOS DEL SUELO EN LAS CERCANÍAS DE FALLAS GEOLÓGICAS: EXPLICACIÓN DEL PROTOCOLO TÉCNICO DEL DECRETO EJECUTIVO 32967 - MINAE, ANEXO 3
}

\author{
THE DEFINITION OF LAND USE IN THE SURROUNDINGS OF GEOLOGICAL \\ FAULTS: TECHNICAL EXPLANATION OF THE PROTOCOL OF EXECUTIVE \\ ORDER 32967 - MINAE, ANNEX 3
}

\author{
Allan Astorga-Gätgens \\ Profesor Escuela Centroamericana de Geología, UCR \\ Consultor en Gestión Ambiental Integral y Ordenamiento Territorial \\ Apdo. 480 - 2070, San José, Costa Rica \\ a.astorga.g@gmail.com
}

(Recibido: 04/02/2013 ; aceptado: 26/11/2013)

\begin{abstract}
A technical explanation of the protocol published as Executive Order (32967 - MINAE, Annex 3) is performed here. The protocol concerns the definition of land use in the surroundings of inactive, active and potentially active faults. Besides clarifying the technical nomenclature, this text explains the procedure that the professional geologist should follow to establish the possible safety areas to be respected when defining land uses, particularly for construction. It also examines the scope of the technical report and its implications regarding the use of the property. Finally, the implementation of the Protocol in Costa Rica is discussed and its importance in the development of management and land planning.

Keywords: Geologic fault, zonification, land use, trace fault, security zone, technical protocol.

RESUMEN: Se realiza una explicación técnica sobre el Protocolo Técnico publicado como Decreto Ejecutivo (32967 - MINAE, Anexo 3). El Protocolo se refiere a la definición de los usos del suelo en las cercanías de fallas geológicas inactivas, activas y potencialmente activas. Aparte de aclarar la nomenclatura técnica, se explica el procedimiento que debe seguir el profesional en geología para establecer las eventuales zonas de seguridad que deben respetarse al momento de definir los usos del suelo, en particular para las construcciones. También se analiza el alcance del dictamen técnico y sus implicaciones respecto al uso de la propiedad. Finalmente, se discute la aplicación del Protocolo en Costa Rica y su importancia en el desarrollo de ordenamiento y planificación del territorio.

Palabras clave: Falla geológica, Zonificación, Uso del Suelo, Traza de Falla, Zona de Seguridad, Protocolo Técnico.
\end{abstract}




\section{INTRODUCCIÓN}

Para casi todos es conocido que Costa Rica es un país geológicamente activo. Como tal, está atravesado por una significativa cantidad de fallas geológicas (ver Denyer et al., 2003).

La observación del Atlas Tectónico de Costa Rica (Denyer et al., 2003), elaborado a una escala regional (1:200.000), deja ver esa realidad. A mayor escala, es muy probable que la cantidad de fallas geológicas sea mucho mayor.

Algunas de las fallas geológicas que tienen expresión en superficie, pueden ser fallas activas o potencialmente activas. De esta forma, si la actividad de la falla se da en la cercanía de la superficie del suelo, la falla puede producir una ruptura en la superficie, dañando las obras de infraestructura que puedan disponerse sobre la traza o la zona de ruptura.

En razón de lo anterior, la identificación y determinación de una falla geológica activa $o$ potencialmente activa, tiene efectos directos en la definición de usos del suelo, en particular para actividades urbanas, de conformidad con la Ley de Planificación Urbana (Ley 4220).

Según esta ley, la zona de riesgo de ruptura en superficie por falla geológica, califica como una Zona Especial, por lo que se deben establecer restricciones o dado el caso, prohibiciones del uso del suelo para el desarrollo de obras constructivas. Lo cual se ajusta muy bien con el concepto preventivo de la gestión del riesgo que establece la Ley Nacional de Emergencias (Ley 8488).

En razón de que, desde el año 2002 (Resolución No. 2002 - 01220), la Sala Constitucional ordenó que los planes reguladores (de uso del suelo) tienen que realizar un "examen de la evaluación de impacto ambiental", el Poder Ejecutivo, por medio del Reglamento General de Procedimientos de Evaluación de Impacto Ambiental -EIA- (Decreto del Poder Ejecutivo Número 31849) formalizó en el año 2004 ese requisito para los planes reguladores y cualquier tipo de ordenamiento territorial.

En el año 2006, mediante el Decreto del Poder Ejecutivo No. 32967, se formaliza el procedimiento de introducción de la variable ambiental en los planes reguladores y cualquier otro tipo de ordenamiento territorial y como parte del mismo, estableció el Protocolo de "Zonificación y restricciones al uso del suelo sobre o en el ámbito territorial inmediato a Fallas Geológicas Activas".

Ese protocolo fue elaborado por una Comisión Técnica con la participación de diversas entidades, como la Cámara de Construcción, la Comisión Nacional de Prevención de Riesgos y Atención de Desastres (CNE), la Universidad de Costa Rica, el Colegio Federado de Ingenieros y Arquitectos, el Instituto Nacional de Vivienda y Urbanismo, el Instituto de Fomento y Asesoría Municipal IFAM y la Secretaría Técnica Nacional Ambiental (SETENA), entre otros. El Protocolo representa una adaptación para Costa Rica del protocolo vigente en el estado de California, Estados Unidos de América, desde hace varias décadas (Bryant, W.A. \& Hart, E.W. (2007)).

En el presente documento se hace una síntesis informativa sobre el Protocolo, su metodología básica y sobre su alcance y aplicación práctica para nuestro país.

\section{DEFINICIONES BÁSICAS}

Las definiciones principales que incluye el Protocolo, son:

Falla: Se define como una fractura o una zona de fracturas cercanamente espaciadas a lo largo de las cuales las rocas de un lado han sido sometidas a un desplazamiento respecto de las rocas del otro lado.

Falla Potencialmente Activa: Fallas que muestran evidencias de desplazamiento superficial durante el Cuaternario (últimos 1.6 millones de años), también denominada como Falla Neotectónica.

Falla activa: Falla (geológica) que ha tenido desplazamientos superficiales durante el Holoceno (últimos 11.000 años) y que tiene potencial de desplazamientos futuros a lo largo de uno o más de sus segmentos, constituyendo una amenaza potencial a estructuras localizadas sobre su traza. Los desplazamientos pueden ser observados directamente o inferidos a lo largo de la traza de falla o en parte de ella.

Falla de trazo definido: Una falla es considerada como de trazo definido si su traza es claramente 
detectable por un geólogo entrenado como un rasgo físico en o ligeramente bajo el suelo. Puede ser identificada por observación directa o métodos indirectos. La consideración critica es que la falla o parte de ella pueda ser localizada con suficiente precisión y seguridad para indicar que las investigaciones necesarias de sitios específicos pueden ser exitosas.

Traza de falla: Es la línea formada por la intersección de la falla (geológica) y la superficie de la tierra, y es la representación de una falla sobre un mapa, incluyendo mapas de zonas de fallas sísmicas. La traza de la falla puede ser simple o compuesta.

Zona de Falla: Una zona de falla es una zona de fallas relacionadas comúnmente, están entrelazadas y son subparalelas, pero pueden ramificarse y ser divergentes. Una zona de falla tiene una anchura significativa (con respecto a la escala de la falla que está siendo considerada o investigada) desde pocos metros hasta varios kilómetros.

Zonas de fallas sísmicas: Son áreas delimitadas por el geólogo, las cuales abarcan las trazas de más de una de las fallas activas.

Estructura de ocupación humana: Es cualquier estructura o infraestructura usada o con el propósito de albergar o proteger cualquier uso $\mathrm{u}$ ocupación, de la cual se espera que se sirvan o dependan directamente de ella una ocupación humana mayor de 2000 personas-hora por año.

Infraestructura estratégica: son aquellas obras que por su envergadura, costo de inversión, uso e importancia resultan de gran valor estratégico para el desarrollo de las actividades humanas y su calidad de vida tales como puentes, pistas de aterrizaje, puertos, túneles, represas, y rellenos sanitarios.

\section{EL PROCEDIMIENTO}

De previo a la explicación del procedimiento, se hace necesario señalar que el mismo se desarrolla, sobre la base de que en el país no se cuenta todavía con cartografía geológica oficial de detalle (escalas igual o menores de 1:25.000), por lo que la forma de resolverlo es que se haga como parte de los estudios ambientales que solicita la legislación.
Tanto en lo referente al análisis de un espacio geográfico para una evaluación de impacto ambiental de un proyecto, como para un plan regulador, la legislación vigente señala que se requiere hacer un reconocimiento de la condición de geoaptitud de terreno (ver Astorga \& Campos, 2001).

Como parte de ese concepto, se establece que se haga una caracterización, a escala detallada (igual o menor de 1:10.000) de la geología, la geomorfología, las condiciones hidrogeológicas (considerando datos de pozos y extrapolación de información geológica), la estabilidad de laderas y la vulnerabilidad a diversos tipos de amenazas naturales.

Como parte de las amenazas naturales, entre otros factores, se incluye el potencial de fractura en superficie por falla geológica activa.

Esto quiere decir que un geólogo, cuando realiza el estudio de geoaptitud de un espacio geográfico dado, para el cual ha identificado la existencia de una falla geológica, debe señalar si la misma es inactiva, potencialmente activa o bien activa. Ello a fin de indicar si se requiere o no el establecimiento de una "zona de seguridad" y la realización de un estudio geológico - neotectónico de la falla que permita precisar el tema de la zona de seguridad o de restricción uso del suelo.

El procedimiento señala que el geólogo responsable, basado en la información previa disponible, los datos de fotointerpretación, del modelo digital del terreno (de ser posible) y los datos de campo, debe señalar con un grado de certidumbre satisfactorio si la falla califica como inactiva o no.

En caso de que no califique como inactiva, deberá calificar la falla como "potencialmente activa" y establecer una zona de seguridad preliminar de 50 metros de ancho a ambos lados de la traza de la falla o de la zona de falla.

Esa zona de seguridad se registrará en el mapa y califica como una Zona Especial, con restricciones técnicas al uso del suelo, hasta tanto un estudio geológico - neotectónico de mayor detalle derive conclusiones más precisas.

El estudio geológico - neotectónico debe ser realizado por un geólogo calificado. Además de la información geológica y geomorfológica previa, debe realizar mayor detalle de campo, incorporación de datos del registro sísmico, así como datos 
de trincheras abiertas en el terreno, paleosismología, apoyo en dataciones radiométricas cuando sea posible y en métodos geofísicos. Como producto del análisis, debe llenarse una Ficha Técnica, cuyo formato se presenta como Apéndice 1 del Protocolo, con la respectiva calificación de certidumbre de la información generada.

El principal objetivo del estudio geológico neotectónico es determinar si la falla geológica es activa y si tiene potencial de ruptura en superficie.

Como producto del estudio geológico - neotectónico, el geólogo y siempre que se tenga el criterio técnico, puede reducir la zona de seguridad de 50 a 15 metros, e incluso a 10 metros, cuando compruebe que no hay ramificaciones a partir de la traza de la falla (Fig. 1).

Es importante aclarar que en el caso de zonas de falla anchas, el ancho de la zona de seguridad puede ser de hasta 100 metros, además del ancho de la zona de falla misma.

\section{ALCANCE Y APLICACIÓN}

El Criterio Específico (a) del Protocolo señala que ninguna estructura de Ocupación Humana será permitida sobre la traza de una falla geológica activa o de su zona de seguridad, definida por un estudio geológico - neotectónico, o bien de forma preliminar para la zona de seguridad de 50 metros si no se tiene el estudio geológico - neotectónico.

Por su parte, el Criterio Específico (b) del Protocolo indica que en el caso de infraestructura estratégica (como hospitales, centros comerciales, edificaciones mayores, etc.) se aplicará la alternativa de diseño que evite pasar por la traza de la falla y su zona de seguridad establecida por el estudio geológico - neotectónico.

El Criterio indicado, señala además de que en el caso extremo de "que fuese materialmente imposible evitar que la obra de infraestructura no pueda cumplir lo anterior, se procederá a establecer un parámetro de diseño y construcción más estricto". Esto con el fin de minimizar los eventuales daños y además, se señala que deberá contarse con un plan de mitigación de desastre.

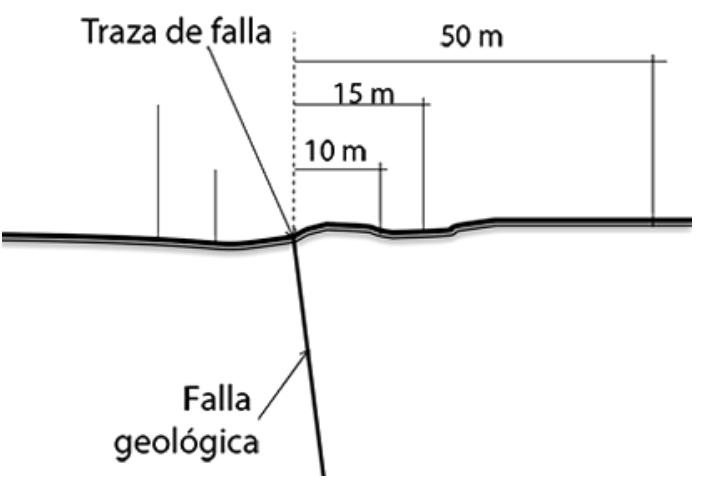

Fig. 1: Esquema ilustrativo de una falla geológica y su traza, y las zonas de seguridad establecidas según criterios del estudio geológico - neotectónico.

El Protocolo señala que el estudio geológico - neotectónico "solo tendrá aplicación para el área de estudio en que se circunscribe". De manera que su extrapolación a otras áreas, debe complementarse con información técnica de dicha zona.

Señala también en el caso de que otro geólogo realice un estudio en un área adyacente o complemente uno previo, y en caso de que sus resultados difieran del primer estudio y adyacente, "deberá presentar sus argumentaciones por medio de una discusión técnica en el informe y pondrá peso a sus resultados en consideración de la calificación de certidumbre que considera tienen dichos resultados".

Finalmente, se indica que en caso de que exista información disímil, podrá sujetarse el resultado de ambas investigaciones a un arbitraje por medio de un experto debidamente acreditado por la CNE.

\section{IMPORTANCIA DE SU USO}

Como se indicó previamente, la identificación de una falla geológica, y la determinación de si es inactiva, potencialmente activa o activa, así como su zona de seguridad tiene la finalidad de realizar gestión preventiva del riesgo y evitar que se produzcan daños a la infraestructura humana, y con ella a las personas. 
El Protocolo aplica solamente para obras de infraestructura nuevas y para planificación territorial. No tiene carácter retroactivo, excepto que los propietarios de los terrenos o edificaciones así lo deseen.

El Protocolo señala que todo comprador de un terreno tiene derecho a conocer si el mismo es atravesado o no por una falla geológica activa o potencialmente activa.

Además, en el caso de que un terreno en cuestión haya sido objeto de un estudio geológico local que aporte datos sobre la naturaleza geológica del terreno y que sean de conocimiento o propiedad del vendedor, éste podrá aportarlos al comprador como parte de la negociación.

En el caso de que ya existan obras de infraestructura (ocupación humana), dentro de un área de seguridad o de traza de falla identificada por medio de un estudio técnico que ha hecho uso del Protocolo, se aplicarán los siguientes lineamientos:

a) La autoridad municipal informará a los propietarios de esos bienes inmuebles sobre la situación;

b) Indicará a los mismos que deberán establecer medidas técnicas de reforzamiento estructural y de prevención, siempre que sea posible.

c) Los propietarios u ocupantes de las edificaciones dispondrán de un plan de emergencia en caso de sismos elaborado por un profesional especialista en la materia, que implique la evacuación de las estructuras más vulnerables.

d) Se promoverá que a futuro no se den ampliaciones que impliquen la llegada de nuevos habitantes a las estructuras y se promoverá un gradual proceso de desmotivación al proceso de ocupación de los terrenos específicos vinculados con el área de seguridad establecida.

Por último, el Protocolo señala que para que los estudios geológicos adquieren oficialidad una vez que se presenten y registre en la CNE. Ello, en aplicación de los principios de prevención del riesgo natural, de responsabilidad técnica, social y ambiental, de certificación y acreditación y de ética y responsabilidad profesional incluidos en el Protocolo.

\section{DISCUSIÓN Y CONCLUSIONES}

La posibilidad que ha tenido el autor de conocer numerosos informes geológicos presentados por profesionales en geología, consultores ambientales como parte del trámite de EIA, deja ver que no se está aplicando de forma sistemática y apropiada el Protocolo de Fallas Geológicas aquí descrito.

Esto requiere ser corregido y mejorado a fin de que dichos profesionales tengan claro conocimiento de la responsabilidad profesional que asumen al momento de firmar un documento técnico que forma parte de un expediente ambiental ante el Estado.

Al respecto, se considera relevante la mayor divulgación posible del Protocolo, razón de ser de este documento, así como de un programa de capacitación o refrescamiento a geólogos consultores ambientales registrados ante la SETENA.

\section{REFERENCIAS BIBLIOGRÁFICAS}

ASTORGA, A. \& CAMPOS, L., (2001): El cartografiado de geoaptitud de terrenos.- Rev. Geol. Amer. Central, 24: 103-110.

BRYANT, W.A. \& HART, E.W., (2007): Fault Rupture hazard zones in California. Alquist - Priolo Earthquake Fault Zoning Act with Index to Earthquake Fault Zones Maps.42 págs. Department of Conservation, California Geological Survey, California.

DENYER, P., MONTERO, W. \& ALVARADO, G., (2003): Atlas Tectónico de Costa Rica.55 págs.- Editorial Universidad de Costa Rica, San José. 
